This is the Accepted Version of the author's manuscript published as:

Gonçalo Paiva Dias (2019). Fifteen years of e-government research in Ibero-America: a bibliometric analysis. Government Information Quarterly, 36(3), 400-411. https://www.doi.org/

$\underline{10.1016 / \text { i.giq.2019.05.008 }}$

(c) 2019. This manuscript version is made available under the CC-BY-NC-ND 4.0

license http://creativecommons.org/licenses/by-nc-nd/4.0/

\title{
Fifteen years of e-government research in Ibero-America: a bibliometric analysis
}

\section{Gonçalo Paiva Dias ${ }^{\text {a }}$ *}

${ }^{a}$ School of Technology and Management of Águeda, Research Unit on Governance, Competitiveness and Public Policy, Universidade de Aveiro, Apartado 473, 3754 - 909, Águeda, Portugal, gpd@ua.pt, phone: +351234611 500; fax: +351234611540

${ }^{*}$ Corresponding Author

Abstract In this article it is presented a bibliometric analysis of e-government research in the Ibero-American (IA) Community. Data from the Scopus ${ }^{\circledR}$ database relating to 1,129 research documents published between 2003 and 2017 was used. Presented analyzes include the most productive and impacting researchers, institutions and countries; determinants for country results; most relevant subject areas and specific research themes; and international cooperation patterns, namely within the IA Community. Contrary to what happens worldwide, e-government research production is still rising in Ibero-America. Besides the general heterogeneity, there are four relatively homogenous groups of countries to what concerns production and impact: leading, evolving, emerging, and expectant countries. IA has distinctive characteristics that make it interesting as an object of study and that constitute an opportunity for further development. Nevertheless, for results to continue to evolve, it is relevant that public policies related to e-government development and the promotion of research continue to be developed and that cooperation among IA researchers is properly promoted and supported.

Keywords: e-government; bibliometrics; scientometrics; citation analysis; Ibero-America; Iberian Peninsula; Latin America 


\section{Introduction}

The oldest research articles using the expression 'electronic government' in their titles, keywords, or abstracts indexed in Clarivate Analytics Web of Science ${ }^{\mathrm{TM}}$ or the Elsevier Scopus ${ }^{\circledR}$ databases were published in 1996 (Milward \& Snyder, 1996; Perritt, 1996). Before that, the expression only appears as part of broader contexts like 'electronic government information', 'electronic government data', or 'electronic government documents.' The first indexed article using the term 'e-government' was published three years later (Deb, 1999). The origin of the term is nevertheless older than that. According to Heeks and Bailur (2007, p. 244), "e-government seems to have first come to prominence in 1997", after 'electronic government' had been used in the 1993 U.S. National Performance Review. Since then, thousands of articles on the subject have been published and indexed in the main research databases.

Ibero-America (IA) is a community of countries bounded by strong historical and cultural links. It includes the two European countries that constitute the Iberian Peninsula (Portugal and Spain) and all the Portuguese and Spanish speaking countries in Latin America (Argentina, Bolivia, Brazil, Chile, Colombia, Costa Rica, Cuba, Dominican Republic, Ecuador, El Salvador, Guatemala, Honduras, Mexico, Nicaragua, Panama, Paraguay, Peru, Puerto Rico, Uruguay and Venezuela). These countries are joined in the Organization of Ibero-American States for Education, Science and Culture (OEI), which is heir of the Office of Latin American Education, created in 1949 (Organization of Ibero-American States for Education, Science and Culture, 2018). Since 1991 the heads of state and government of IA states have met annually in the Ibero-American Summit (formally the Ibero-American Conference of Heads of State and Governments).

Due to the historical and cultural links that exist between IA countries and to the fact that the development of science is among the original objectives of the OEI, it seems relevant to study research development in this Community and to what extent that development is being achieved by means of cooperation within IA or has the potential to be fostered by promoting that cooperation. With this article, we contribute to that effort by studying the case of e-government research.

Thus, the main goal of this study is to analyze e-government research publication trends in IA as a tool to foster future cooperation within that community. This is useful 
because, according to Glänzel, Schubert and Czerwon (1999, p. 185), scientific cooperation of the EU countries with economies in transition and developing economies "is particular advantageous for less developed countries, but also highly industrialized countries benefit from it". The research questions underlying the study are: How has e-government research production evolved and what is its potential for further evolution? What is the distribution of this production among the IA countries and what explanatory factors are associated with that distribution? Are there any distinctive characteristics of e-government published research in the IA Community that differentiates it in the world? Is cooperation inside the Community relevant to explain the results and, if so, what is the potential for its further development?

Specific objectives include: (i) assessing the evolution of the IA production and of its impact; (ii) finding the most productive and impacting countries, institutions and researchers; (iii) identifying the most relevant subject areas and specific research themes; (iv) evaluating to what extent country results are related to general development of e-government and of research; and (v) evaluating the relevance of international cooperation, namely within the IA Community, to the results. A bibliometric analysis is used to pursue these objectives. Implications of the results are also discussed.

To our knowledge, the bibliometric analysis presented in this article is the first to address e-government research in IA countries. The presented results can be useful for researchers, research managers and research policy makers of the studied countries, as well as of other regions of the globe, namely as a source for the definition of public policies and for benchmarking. For the field as a whole, results may be relevant to understanding regional and transregional research cooperation patterns and their potential to foster global e-government research.

The remainder of this article is organized as follows: in Section 2 we present the theoretical references used in the study; in Section 3 we present the methods used to collect and analyze the data; in Section 4 we present the results of the bibliometric analysis; in Section 5 we discuss the main findings and the limitations of the study; and, finally, in Section 6 we formulate the general conclusions and their main implications.

\section{Theoretical references}


In this section we present theoretical references that underlie the study: first, we address e-government research as the object of the study; second, we introduce bibliometrics and present bibliometric techniques used in the study; and third, we present a review of bibliometric analyses on e-government research performed by other authors.

\subsection{E-government research}

According to Relyea (2002, p. 31), "e-government is a dynamic concept of varying meaning and significance". Indeed, several conceptions of e-government coexist, ranging from the 'simple' use of Information and Communication Technology (ICT) to enhance relations of government with citizens and businesses to a more or less ambiguous symbol of a better government. Despite this diversity, it can generally be assumed that e-government research deals with the study of ICT usage by governments in its different but complementary and interrelated dimensions (e.g. technical, administrative, political). Thus, e-government can be described as a field of multidisciplinary applied research with links to several well established disciplines. This nature of e-government research has been previously acknowledged by various authors. According to Heeks and Bailur (2007, p. 252), for example, "e-government can be seen as sitting at the cross-roads between a number of other research domains, particularly computer science, information systems, public administration, and political science".

Bearing that in mind, in this study, instead of choosing a specific e-government definition and research approach and narrowing our analysis to cope with them, we assume that e-government is a somehow diffused construct and that different authors may refer to it using different conceptions and from different research perspectives. This approach has the advantage of including all the richness of e-government research, which is essential for our purposes, but requires that special care is taken to avoid simplistic conclusions based on direct comparisons of bibliometric data relating to different research disciplines.

\subsection{Bibliometrics}

The term bibliometrics was originally proposed and defined by Pritchard (1969) as "the application of mathematics and statistical methods to books and other media of communication". It includes methods such as content analysis, text analysis, citation 
analysis, keyword co-occurrence, co-citation analysis, or co-authoring analysis. These methods are widely used in bibliographic, scientometric and linguistic studies, for example.

When applied to academic research, bibliometrics can be defined as a set of methods to quantitatively analyze academic literature (de Bellis, 2009). The most common indicators in bibliometric studies of research include: the number of publications, as an indirect measure of knowledge production; the number of citations, as a measure of scientific impact and international visibility (Jones, Huggett, \& Kamalski, 2011); average citation per article, as a comparative measure of impact regardless of differences in the number of articles published per year (Canavero et al., 2014); the $h$-index, as a representative measure of scientific achievement (Hirsch, 2007; Braun, Glänzel, \& Schubert, 2006); and co-authorship, as an indicator of collaboration (Aksnes, 2013).

Despite its usefulness, the interpretation of bibliometric results should be made with caution. The first and more debated misuse of bibliometrics is related to the fact that impact, as measured by citation indicators, does not necessarily mean quality. Another aspect is that different subject areas tend to have very different publication and citation patterns, thus direct comparison of publication and citation metrics for different scopes has to be used with care. The selection of the sets of articles to be analyzed using these techniques also needs attention since results largely depend on those sets. Thus, it must be assured that the available data is sufficient and that the selected publication types, field definitions and publication and citation years are adequate to the intended purposes (Pendlebury, 2009).

\subsection{Related Work}

Although its usefulness is recognized, bibliometric analyses are relatively scarce in egovernment. In this section, we review some of the previous studies that applied bibliometric techniques to e-government literature.

Five of the identified studies address e-government research globally, i.e., do not address a specific region or community. Using this approach, Cheng and Ding (2012) performed a bibliometric analysis on 2,232 journal articles from the Science Citation Index ${ }^{\mathrm{TM}}$ (SCI) and the Social Science Citation Index ${ }^{\mathrm{TM}}$ (SCCI) to conclude that "cross-sectoral collaboration", "construction of e-government" and "security infrastructure design" were the pivotal points present in the literature and that "performance evaluation" was the research 
front of e-government. Also using Web of Science ${ }^{\mathrm{TM}}$ as a source, Almeida, Zouain, and Mahecha (2014) analyzed data from 4,225 journal articles and conference proceedings to find that nearly $80 \%$ of the citations were concentrated in the ten most cited countries, and that the publication of articles in reputable journals was pivotal for these results. In another study, Ismayilova (2014) used Google Scholar ${ }^{\mathrm{TM}}$ data to perform a bibliometric analysis on 381 egovernment materials published between 2000 and 2014 to conclude that technological and development issues and e-government applications were the most researched subjects and that the most productive authors were affiliated to the best institutes of the USA, Singapore and the UK. More recently, Rodríguez Bolívar, Alcaide Muñoz, and López Hernadéz (2016) performed a bibliometric analysis on 826 e-government articles published between 2000 and 2012 in 'Science \& Library Science' and 'Public Administration' journals listed in Web of Science $^{\mathrm{TM}}$ to concluded that the topics most often considered were 'e-participation', 'new technologies and management procedures', 'online public services', 'evaluation of egovernment initiatives' and 'transparency, information disclosure and accountability'. Relating IA, they concluded that a large number of studies addressed new technologies as tools "to assist governments in improving public involvement, in fighting corruption, in institutionalizing the transparency of public-sector practices“(Rodríguez Bolívar, Alcaide Muñoz, \& López Hernadéz, 2016, p. 67). In another study, Alcaide-Muñoz et al. (2017) used a science mapping approach to analyze the thematic evolution of the e-government field. They performed a keyword based analysis on 8,094 documents published between 2000 and 2016 to conclude that the e-government research is a field in constant evolution that has not yet reached a stage of maturity, especially in what concerns themes such as 'smart cities', 'eparticipation' and 'citizen's acceptance'.

Three other studies used specific communities to conduct their analyses. In one study, Dwivedi (2009) analyzed 41 e-government publications from Transforming Government: People, Process and Policy (TGPPP) to found that "analytical, descriptive, theoretical and conceptual methods were the most dominant research approaches utilized" and that most contributions were from authors "with an information systems background, followed by business and computer science and IT”. In another study, Erman and Todorovski (2010) applied social network analysis to study collaborations within the International Conference on e-Government (EGOV) community and found out that sub-communities were characterized by the geographical distribution of the core authors and by the prevalence of 
specific research topics. More recently, Joseph (2013) used data from Government Information Quarterly (GIQ) to concluded that almost half of e-government studies were either conceptual or relied on secondary data for analysis; that Europe, North America and Asia provided the primary focus of the analyzed research; and that there was no specific topic dominating e-government research.

Relating IA countries, Dias (2016) published a bibliometric analysis of the Portuguese e-government research using the Scopus ${ }^{\circledR}$ database as a source to concluded that the most frequent research topics were 'interoperability and service integration', 'strategies and methodologies' and 'quality, accessibility and usability' and that in order for the Portuguese e-government research to evolve more researchers should be involved; international cooperation should be developed; and more attention should be given to the study of the determinants of the country's success in the provision of e-government services. In another study, Przeybilovicz, Coelho, and Cunha (2014) conducted a bibliometric and sociometric analysis of 124 e-government articles published in Brazilian journals and conference proceedings from 2007 to 2012 to concluded that there was the need for greater interaction between Brazilian researchers; for the use of theories on which to base arguments and findings; and for greater efforts to publish papers in high-level international journals. The most frequently identified research topics were 'e-administration', 'digital inclusion', 'eparticipation' and 'e-governance'.

The review presented here shows that previous bibliometric studies on e-government research vary on their scope (international, specific research communities, a single country), the sources used (selected conferences, selected journals, general research databases), and variables that are studied. In view of the diversity of objectives, the conclusions are naturally diverse. Nevertheless, some trends can be identified: the relevance of co-authoring networks; the importance of international cooperation; the impact of publishing in international journals; the prevalence of publications made by researched affiliated with institutions in Europe, North America and Asia; and the diversity and evolution over time of the most researched topics. No study addressed the IA Community as a whole or any other specific region or community of the globe. For comprehensive studies, four general research databases were used: Web of Science ${ }^{\mathrm{TM}}$; Scopus ${ }^{\circledR}$; Google Scholar ${ }^{\mathrm{TM}}$ and EGRL. The most common studied variables were research topics; research methods; collaboration networks; most productive and cited authors, institutions, and countries; and the most relevant journals. 


\section{Methods}

The data analyzed in this study was retrieved from the Scopus ${ }^{\circledR}$ database. This database was used because it retrieved more entries for the intended search conditions than other sources, namely Web of Science ${ }^{\mathrm{TM}}$, thus implying a bigger sample. The facts that "correlations between the measures obtained with both databases for the number of papers and the number of citations received by countries, as well as for their ranks, are extremely high" and that "there is also a very high correlation when countries' papers are broken-down by field" (Archambault et al., 2009) were also relevant to this choice. The use of other data sources was not considered because they offered a lower coverage (e.g. EGRL) or because they included documents and citations from unpublished material not subject to peer review (e.g. Google Scholar). The combination of different sources was discarded due to the different bases used to compute citations.

Data was retrieved on the $31^{\text {st }}$ July 2018 using the online search engine of the database. The search conditions included all articles having the expressions 'electronic government', 'governo eletrónico', 'governo eletrônico', 'gobierno eletrónico', ‘egovernment', 'e-gov', 'egovernment', 'egov' or 'digital government' in their title, abstract or keywords for which any of the IA countries appeared as an affiliation country, in a fifteen year window, starting in 2003 (see expression 1). This sample window was selected because only since 2003 there has been a number of articles published annually that justifies consideration (18 articles). Since e-government is a transversal topic, all available subject areas were included in the query. A similar approach was used by Dias (2016) in his study for Portugal.

(TITLE-ABS-KEY( $\{$ e-government $\})$ OR TITLE-ABS-KEY $(\{\mathbf{e - g o v}\})$

OR TITLE-ABS-KEY(egovernment) OR TITLE-ABS-KEY(egov)

OR TITLE-ABS-KEY(\{digital government $\})$

OR TITLE-ABS-KEY(\{electronic government $\})$

OR TITLE-ABS-KEY(\{governo eletrónico $\})$

OR TITLE-ABS-KEY (\{governo eletrônico $\})$

OR TITLE-ABS-KEY(\{gobierno electrónico $\}))$

AND (AFFILCOUNTRY(argentina) OR AFFILCOUNTRY(bolivia)

OR AFFILCOUNTRY(brazil) OR AFFILCOUNTRY(chile) 


\author{
OR AFFILCOUNTRY(colombia) OR AFFILCOUNTRY( $\{$ costa rica $\})$ \\ OR AFFILCOUNTRY(cuba) OR AFFILCOUNTRY(\{dominican republic $\})$ \\ OR AFFILCOUNTRY(ecuador) OR AFFILCOUNTRY( (el salvador $\})$ \\ OR AFFILCOUNTRY(guatemala) OR AFFILCOUNTRY(honduras) \\ OR AFFILCOUNTRY(mexico) OR AFFILCOUNTRY(nicaragua) \\ OR AFFILCOUNTRY(panama) OR AFFILCOUNTRY(paraguay) \\ OR AFFILCOUNTRY(peru) OR AFFILCOUNTRY(Portugal) \\ OR AFFILCOUNTRY(\{puerto rico\}) OR AFFILCOUNTRY(spain) \\ OR AFFILCOUNTRY(uruguay) OR AFFILCOUNTRY(venezuela) ) \\ AND PUBYEAR $>\mathbf{2 0 0 2}$ AND PUBYEAR $<\mathbf{2 0 1 8}$
}

The search expression was defined after detailed tests and consideration.

Simplifications of the Portuguese and Spanish expressions "governo eletrónico", "governo eletrônico" and "gobierno eletrónico" were not included because they were redundant with the other. To some extent, the same was true for other expressions related to e-government such as 'digital democracy' or 'electronic governance'. One possible reason for this is that all articles related to e-government are usually indexed using the 'e-government' keyword, either by their authors or for indexation purposes, and the keyword field was included in the search conditions. Still, some documents might have been affected by these choices.

Relating the data, no documents were available with authors affiliated to institutions in Cuba, Guatemala, Nicaragua and Panama. Thus, we ended up with a set of documents from only 18 of the 22 IA countries. In subsequent analyses, only the countries with documents in the data set are considered and represented.

For the 18 eligible countries, a set with a total number of 1,129 documents was retrieved. This includes 618 conference papers (54.7\%), 356 articles (31.5\%), 121 book chapters $(10.7 \%), 18$ reviews $(1.6 \%)$, ten books $(0.9 \%)$, and six editorials $(0.5 \%)$.

Considering source types, 515 documents were published in conference proceedings (45.6\%), 358 in journals (31.7\%), 127 in books (11.2\%), 124 in book series (11.0\%), and five in trade publications (0.4\%). Concerning a language, 1,010 documents were written in English (87.2\%), 83 in Spanish (7.2\%), 63 in Portuguese (5.4\%), one in Catalan, and one in Croatian. 
A bibliometric analysis was then performed on the set of 1,129 documents. Specifically, the following items were analyzed:

- Number of documents published by year;

- Number of citations by year;

- Number of documents by country, author and affiliation institution;

- Number of citations by country, author and affiliation institution;

- Per country, per author and per affiliation average number of citations by article;

- Per country, per author and per affiliation $h$-index;

- Number of documents published by subject area and preferred subject areas for the most relevant authors and institutions; and

- Per country number and percentage of documents co-authored with authors from other nationalities inside and outside the IA Community;

Statistical cluster analysis was used to define clusters of countries with regard to documents published and citations received. To identify possible reasons for the results obtained by different countries, correlation studies were performed using country data on egovernment and e-participation development and selected scientific indicators. For citation related studies, only citations received till the end of 2017 were computed.

To identify the main themes of e-government research in IA and compare them with the whole world, keyword co-occurrence and content analyzes techniques were combined. A six-step approach was used: (i) generation of an auxiliary database with all documents published worldwide by using Expression 1 without geographical restrictions; (ii) identification of the most frequent keywords used in the world (using the auxiliary database) and the IA (using the original database); (iii) discharging of the ambiguous and nonsignificant keywords (keywords not related to a specific e-government research theme); (iv) categorize the relevant keywords in order to identify the main themes; (v) build and carefully test search expressions appropriated to identify documents addressing those themes; and (vi) run multiple searches on both databases to identify the documents addressing each theme 
worldwide, in the IA Community, and in each of the identified clusters. Keyword cooccurrence has previously been used by Alcaide-Muñoz et al. (2017) to study the dynamics of the e-government research field (see Section 2.3).

\section{Results}

In this section we present the results obtained from the investigation. The section is subdivided into eight subsections which present results relating the country clusters; evolution of the research production; determinants for country results; main subject areas; specific research themes; most productive authors; most productive institutions; and international cooperation.

\subsection{Country clusters}

Table 1 presents the number of documents published between 2003 and 2017, the number of citations received by those documents, the average number of citations per document, and the $h$-index by IA country. As can be observed, both the numbers of documents published and the citations received are very heterogeneous in the IA Community.

To identify more homogeneous groups of countries within the Community we performed a statistical clustering analysis using the documents published and the citations received by countries. Both variables were logarithmized with the base 10 logarithm because they had an exponential distribution, and since linearity is a pre-condition for statistical clustering, and logarithmic transformations do not affect the original monotony of variables. The variables were subsequently normalized to the scale $0-1$ to assure that they had even weights in the final model. K-Means clustering method with four clusters was used.

The resulting model is graphically depicted in Figure 1. Four relatively homogeneous clusters of countries have been identified:

- Cluster 1 - Spain, Brazil, Portugal and Mexico constitute the group of leading countries. Their publications range from 163 to 423, the citations received from 589 to 3317 , and the $h$-indexes from 18 to 31 . Altogether these countries account for $85.9 \%$ of the documents published and $92.9 \%$ of the citations received in the IA Community. 
- Cluster 2 - Argentina, Chile, Ecuador, Colombia and Uruguay constitute the group of evolving countries. They have at least 30 documents published or 30 citations received and account together for $14.5 \%$ of the documents and $7.4 \%$ of the citations.

- Cluster 3 - Costa Rica, Peru, Venezuela, Puerto Rico and Dominican Republic constitute the group of emerging countries. Their publication count added to their citations is always higher than 10, ranging from two documents with 16 citations (in the case of Costa Rica) to 11 documents with two citations (in the case of Peru). Together they account for only $3.4 \%$ of all the documents published and $0.8 \%$ of the citations.

- Cluster 4 - Bolivia, El Salvador, Honduras, Paraguay, Cuba, Guatemala, Nicaragua, and Panama constitute the group of expectant countries. Each has at most two documents published and received at most one citation. The group includes the four countries without any documents in the dataset (Paraguay, Cuba, Guatemala, and Nicaragua).

\subsection{Evolution}

The graph in Figure 2 presents the evolution of the number of documents published worldwide and by authors affiliated to institutions in IA countries, from 2003 to 2017. It is visible that while the world production has been declining since 2010, production of the IA Community is still growing. So, having started later, IA researchers are still raising their production. The number of citations received annually is growing steadily in both universes (see Figure 3).

Concerning the evolution within the IA Community, the number of documents published annually by the evolving countries is growing faster than for the leading countries (see Figure 4). So, it seems that the pattern identified earlier in the comparison between the world and the IA Community is also visible within the Community itself, with late starters exhibiting a faster growth. This phenomenon should be seen as natural, since rapid growth is typical of the early stages of innovation processes (Rogers, 2003). Likewise, it can be expected that the same will happen to emerging and expectant countries in the future. However, for the time being, the low number of articles published annually by those countries does not yet allow the identification of such trends. 


\subsection{Determinants for country results}

Concerning possible determinants for country results, we used a correlation study to investigate associations between the numbers of publications and citations for each country and five other variables: the scores of the countries in the UN e-Government Development Index 2016 and in the UN e-Participation Index 2016 (United Nations, 2016); the number of full time equivalent R\&D researchers per million people (average for 2003-2017), the number of scientific and technical journal articles per million inhabitants (2016), and the R\&D expenditures as a percentage of the GDP (average for 2003-2017), as released by the World Bank (2018). These concrete variables were chosen because they constitute measurements of e-government development and of general strength of research. No better alternative indicators were found at international organizations.

The averages of the available observations within the period 2003 to 2017 were used for World Bank data on R\&D researchers and R\&D expenditures since the periodicity of national surveys varies among countries and, with a single year, the number of countries that could be studied would be too restricted to allow solid conclusions. Because normal distribution of all variables cannot be assumed, non-parametric Spearman's correlation was used.

The results of the correlation study are presented in Table 2 . As can be observed, all correlations are significant $(p$-value $<0.01)$ and all selected variables are strongly and positively correlated with both the number of documents and the number of citations per country. Moreover, based on the Kruskal-Wallis test for independent samples, these variables exhibit statistically significant differences for the several clusters identified previously ( $p$ value $<0.01$ ), further validating that clustering. Thus, the results of e-government research in the IA Community are directly associated with e-government development and eparticipation, as measured by the UN, and with general research indicators, as published by the World Bank.

\subsection{Subject areas}

The analysis of subject areas for large sets of documents is not an easy task. Indeed, since it is not practical to read and classify each document directly, researchers have to rely on the classifications previously made when those documents were indexed. As these 
classifications are made according to where the documents were published, a source can be, and usually is, classified in more than one subject area.

To overcome this, based in the fact that 'Computer Science' and 'Social Sciences' are the most relevant original categories (together, they encompass $90.2 \%$ of the documents listed), we defined four derived categories: documents classified in Computer Science but not in Social Sciences; documents classified in Social Sciences but not in Computer Science; documents classified both in Computer Science and Social Sciences; and documents classified neither in Computer Science nor in Social Sciences. This approach has the advantage of 'disentangling' the original categories and allowing the classification of the documents as having been published in technical sciences, in social sciences, or transversal to both. Note that these new derived categories do not overlap, i.e., no document belongs to more than one derived category.

Results for number and percentage of documents published, number and percentage of citations, and average number of citations per document for the derived categories are presented in Table 3. From the Table it is evident that while the majority of the publications were made in technical sciences, publication in social sciences tends to be more impacting.

\subsection{Specific research themes}

In order to identify the main research themes in the IA Community and compare them with those for worldwide e-government research we used a combination of keyword cooccurrence and content analysis techniques, as described in Section 3. Table 4 presents the percentage of documents worldwide and in the IA Community that address each of the identified themes. Absolute and percentage differences between both figures are also presented. The data is sorted by decreasing order of percentage difference in order to facilitate the identification of the more prominent and less prominent themes in the IA Community when compared to the world.

From the Table, it is clear that the themes more directly related to citizenship such as 'e-participation' and 'transparency and accountability' are the object of greater attention in the IA Community than worldwide and that the opposite happens with themes more related to electronic service delivery such as 'service quality', 'security, privacy and trust', and 'adoption and acceptance'. This relevance of citizenship related themes is compatible with 
the prominence of other topics such as 'social media' (mostly an enabler for transparency and participation) and 'local-government' (typically the most direct form of government). Indeed, as can be observed in the Venn diagram of Figure 5, there is a significant overlap between these themes. Although not represented in the Figure, this overlap is greater for IA than for the world.

When this analysis is broken-down by cluster, it shows that the prominences of 'eparticipation', 'transparency and accountability', and 'local government' are transversal to clusters 1 to 3 (note that cluster 4 is irrelevant for this analysis due to the limited number of documents published), while the social media's prominence is transversal to clusters 1 to 2 . Thus, the investigation of topics related to citizenship, namely at the local government level, constitutes a trend that, besides differentiating it in relation to the world, is essentially transversal in the Community.

Besides citizenship related themes, other prominent topics in IA include 'interoperability and integration' (clusters 1 and 2), 'usability and accessibility' (cluster 1), and 'knowledge management' (cluster 1). By not being transversal, these themes contribute to explaining the differences between clusters and, concomitantly, provide opportunities for the development of the less developed ones. Relating the less prominent themes (including those related to electronic service delivery), their underrepresentation is transversal to all the clusters. Thus, they constitute general opportunities for the development of e-government research in the IA Community.

\subsection{Authors}

Table 5 lists all the authors affiliated to institutions from the IA countries with eight or more documents listed in the dataset. This specific threshold was selected in order to minimize subject and regional biases. Indeed, the set of 27 authors presented in the Table encompasses the ten most productive authors in each of the following subsets: documents classified in Computer Science; documents classified in Social Sciences, documents affiliated to Iberian countries; and documents affiliated to Latin American countries. The Table presents information concerning affiliation country, number of documents published, number of citations, average citation per document, $h$-index and percentage of documents published in each of the derived subject areas for each author. 
Together, the 27 authors listed in the Table have authored or co-authored $27 \%$ of all the documents in the dataset and obtained $50 \%$ of all the citations. Eight relevant coauthoring clusters are identifiable:

- Gil-Garcia, Luna-Reyes, Sandoval-Almazan, Luna D.E., Puron-Cid and Picazo-Vela, the Mexican authors in the list, have co-authored, in combinations of two or more, a total of 59 documents, receiving 752 citations;

- Sabucedo and Rifon, from the University of Vigo, Spain co-authored 18 documents which received 60 citations;

- Rocha and Sá, two of the three Portuguese researchers in the list, co-authored all their 12 documents receiving 93 citations;

- Bolivar, Muñoz and López Hernández, three of the eight Spanish authors in the list, co-authored, in combinations of two or three, a total of 12 documents which received 31 citations;

- Torres, Royo and Pina, from the University of Zaragoza, Spain, co-authored, in combinations of two or three, a total of 9 documents which received 756 citations;

- Estevez and Janowski, affiliated to different countries, co-authored 9 documents which received 51 citations;

- Gil-Garcia and Pardo from University at Albany State University of New York coauthored 8 documents receiving 99 citations; and

- Matheus and Ribeiro, two Brazilian researchers affiliated to institutions in the Netherlands and in Brazil, respectively, co-authored 8 documents receiving 35 citations.

Concerning subject areas, the data in Table 5 allows the conclusion that although publication 'oriented' towards social sciences tends to be more impacting (see Section 4.4), the authors with the highest impact are not necessarily 'oriented' towards social sciences. Indeed, the majority of the most impacting authors published most of their works in technical sciences while having greatest impact when publishing in social sciences. More than a 
contradiction, this might be a manifestation of the truly transdisciplinary nature of egovernment research.

\subsection{Research Institutions}

Table 6 lists all the institutions of affiliation with 13 or more documents listed in the dataset. As for the authors, this threshold allows to encompass the ten most productive institutions in Computer Science; in Social Sciences; in the Iberian countries; and in the Latin American countries. Together, these institutions are affiliations of $52.3 \%$ of the documents in the dataset and received $70.9 \%$ of all citations.

In addition to the relationships that naturally result from the co-authoring clusters identified in the previous section, an additional cluster is identifiable: The Universidad de Vigo and the Universidade de Coimbra have eight documents in common. All these documents were co-authored by Sá and Rocha, two Portuguese authors that constitute one of the clusters identified in the previous section, in collaboration with different researchers from the Universidad de Vigo. The Fundação Jertúlio Vargas and Universidade do Estado do Rio de Janeiro have 10 documents in common but were not considered as constituting an additional cluster since all those documents were authored by Joia L.A., who is affiliated to both institutions.

\subsection{International cooperation}

Table 7 shows the total number of documents co-authored internationally both within and outside the IA Community, and the relative weight of these types of documents in the total number of documents. Only IA countries with internationally co-authored documents are represented. The map in Table 8 details these figures for collaborations between each pair of IA countries. It is interesting to note that $55 \%$ of the collaborations are trans-continental, $27 \%$ occur within Latin America and 17\% happen between the two Iberian countries.

Concerning the leading countries (Cluster 1), the weight of documents co-authored with other IA countries ranges from 5\% (in the cases of Brazil and Mexico) to 15\% (in the case of Portugal). Even so, cooperation within the IA Community is important for at least three of these countries, with IA co-authored documents representing relevant percentages of their internationally co-authored documents: 52\% in the case of Portugal; $44 \%$ in the case of Spain; and $25 \%$ in the case of Brazil. The exception is Mexico, with a percentage of only $5 \%$. 
This is in part explained by its strong proximity with the USA (that appears as an affiliation in $88 \%$ of its international co-authored documents).

To what concerns the evolving countries (Cluster 2), the weight of documents coauthored internationally inside the IA Community rages from $22 \%$ in the cases of Argentina and Uruguay to $62 \%$ in the case of Ecuador. These very high percentages suggest that cooperation within the Community has been key to the outcomes achieved by these countries, in particular through joint publication with authors from the group of leading countries (Cluster 1).

With regard to emerging countries (Cluster 3), they have variable patterns of international cooperation: Costa Rica and Puerto Rico have no internationally co-authored documents, while those represent $64 \%$ of the Peruvian documents (55\% co-authored within the IA Community).

\section{Discussion}

In the previous section we presented the results of the study as well as its more direct findings. In this section we discuss some complementary aspects: the relevance of public policies for IA results; the influence that the specific IA contexts might have for more prominent research themes; the potential for further evolution; and the opportunities to further explore internationalization within IA. The section concludes by addressing the limitations of the study.

\subsection{The relevance of public policies}

As described in the previous section, country results are associated with e-government development, the general strength of research, and international cooperation, namely between the IA countries. Although these determinants are relevant to explain global results, their relative importance varies with the concrete cases.

For the two Iberian countries, results are very influenced by the EU agenda and funding. Spain is the IA leader in both the UN rankings and has the highest R\&D expenditure in percentage of the GDP. Portugal is ranked lower in the UN indexes but has the second highest R\&D expenditure in percentage of the GDP and the highest number of researchers in percentage of the population. In both cases, international cooperation within the IA is 
relevant but not determinant. In the case of Mexico, its achievements in e-participation and its close proximity with the USA are the determinant factors. In Brazil, its dimension, together with the third largest R\&D expenditure in percentage of the GDP, seems to be the most influential factor.

Relating to evolving countries (Cluster 2), there is a combined influence of relatively good results in e-government or in e-participation with relevant cooperation with other IA countries, namely from Cluster 1 . The exception is Ecuador that compensates below the average achievements in e-government and e-participation for the cluster it belongs to with a very strong cooperation with Spain.

In the remaining countries, the case of Cuba is noteworthy: although it has relatively good R\&D indicators, including international publications, it is far below the average in eparticipation and e-government development and has no documents in the dataset. This is most likely determined by the country's particular political situation.

In any case, achievements in e-government research appear to be clearly influenced by public policies, both those related to the promotion of research (including its internationalization) and those related to e-government development.

\subsection{Participation and transparency}

As addressed, IA countries publish a higher percentage of documents addressing themes related to transparency and, to a lesser extent, participation, than it happens in the world as a whole. These issues are closely linked to the quality of democracy and, in particular, to the fight against corruption, which are very relevant in the Community as was previously pointed out by Rodriguéz Bolíver, Alcaide Muñoz, and López Hernandéz (2016). In effect, Latin America has, in general, high levels of corruption perception. The subject is also relevant for the two Iberian countries that, in the context of the Western Europe, have above the average corruption perceptions (Transparency International, 2018).

Thus, it is plausible that the relative importance of participation and transparency may be bolstered by the social relevance of these themes in the Community. This can happen directly because of the researchers' interest in socially relevant topics, or indirectly because of the subject's inclusion in e-government development programs. To this respect, Mexico and Brazil are paradigmatic cases. In Mexico, the civic innovation and citizen participation 
constitutes one of the five objectives of the National Digital Strategy (Gobierno de La República, 2013). In Brazil, promoting transparency through the use of ICT and expanding social participation in the life cycle of public policies and services constitute two of the five strategic objectives of the national Digital Governance Strategy (Ministério do Planejamento, Desenvolvimento e Gestão, 2018).

\subsection{Local government}

Contrary to what happens for the world, local government is the most researched egovernment theme in the IA (see Table 4). Moreover, as identified previously, its research is predominantly associated with citizenship related themes such as participation and transparency. Some IA particularities help to explain the phenomenon.

Although Portugal and Spain have a long municipal tradition, the introduction of local democratic governments is relatively recent. In Portugal, it was introduced in 1976 after the Carnations Revolution. In Spain, it was introduced in 1978 following the end of the Franco regime and the transition to democracy. In Latin America, the political autonomy of local government was also gradually introduced in the context of the democratization process that took place from the end of the 1980s. In 2008, "all countries except Cuba had multi-party local government elections" (Nickson, 2011).

Thus, the fact that the local government political autonomy is a relatively recent trend constitutes a plausible explanation for the relevance that this level of government assumes for e-government research in IA and its close connection with citizenship related themes.

\subsection{Potential for further evolution}

Contrary to what happens worldwide, the number of documents published annually by researchers affiliated to institutions in the IA is still growing. There are several reasons to expect that this growth can continue in the near future:

- There is political will for the progress of e-government in IA, namely in the emerging and expectant countries. Some very recent examples of programmatic documents in these countries illustrate this trend: the declaration of national interest in the development of digital government in Peru (Presidencia del Consejo de Ministros, 2018); the new digital transformation strategy in Costa Rica (Gobierno del 
Bicentenario, 2018), and the new digital government strategy in El Salvador (Gobierno de El Salvador, 2018). Since, as it was demonstrated, e-government development and e-government research are associated, it is expected that further development of e-government in emerging and expectant countries will also contribute to promoting e-government research in those countries.

- There is the potential to attract more researchers to the e-government research effort, namely in Latin America. Indeed, this Region "has increased the number of its scientists and research institutions in recent years" and has "many young graduates who enthusiastically wish to make a career in science" if adequate conditions are provided (Ciocca \& Delgado, 2017).

- There are themes in the community that can be further investigated (e.g. the interconnection between transparency, participation, and local government), themes that are transversally underexplored (e.g. service quality, security, decision support), and themes whose research is underexplored in particular clusters (e.g. interoperability, usability, knowledge management). Thus, there are opportunities to produce research which results may be innovative and attract the attention of the international community.

Therefore, e-government research in IA can produce interesting results and, if adequate public policies are deployed, the universe of study can continue to grow and more researchers can join the research effort. This constitutes an opportunity for e-government research to continue to grow in the Community.

\subsection{The internationalization opportunity}

As mentioned before, international cooperation inside the IA Community has proved to be a relevant driver for e-government research. There is a number of reasons why such cooperation can be expected to continue to play an important role in the future:

- Only one of the nine co-authoring clusters identified in Sections 4.6 and 4.7 includes authors affiliated to more than one IA country. This means that international relations between the most productive and impacting authors may exist but they have not yet realized their full potential. 
- The group of evolving countries has high percentages of documents co-authored internationally within the IA Community. With further development of e-government research in these countries it can be expected that the underlying international relations will also continue to evolve and contribute to strengthen IA research results.

- The cooperation of the leading and evolving countries with the emerging countries (Cluster 3) can be strengthened by promoting bilateral or trilateral relations. In fact, there is some evidence that it may already be happening in the case of Peru (with six of its 11 documents being co-authored internationally within the Community). Considering the relevance that the cooperation inside the IA Community had to the results of the evolving countries, this can be a means to promote some emerging countries to the group of evolving countries.

But, once again, public policies are essential if this potential is to be realized. Indeed, although the development of international cooperation will always depend on the concrete will of researchers, some initiatives are essential to promote it: inclusion of the egovernment topics in the national research agendas, availability of funds to finance transnational projects on such topics, agreements and programs to facilitate researcher mobility, and support for researchers' participation in international events.

\subsection{Limitations}

While not calling into question the findings referred to above, there are some limitations associated with the used methods that must be addressed. Above all, it can be argued that the used dataset does not represent all e-government research conducted in IA countries in the past fifteen years because it does not include all published articles and because it does not include other relevant contributions like master and $\mathrm{PhD}$ theses or funded research projects. The sub representation in that dataset of contributions written in languages other than English might also be limiting as research from Portuguese and Spanish speaking countries is at stake. However, it can also be argued that English is the de facto language for publishing research internationally and that contributions resulting from research projects and theses should be published internationally and thus be visible through research databases like the one used. 
Other limitation of the study is that it considers the affiliation country as a base for the identification of authors and documents. This implies that researches from the IA Community that are affiliated to institutions outside the Community may not be included in the study. Similarly, studies about the IA Community that do not involve researchers based in the Community are also not included. Thus, the study addresses e-government research produced in the Community rather than research about the Community or made by nationals of the countries that comprise it. This approach, which stems from the very structure of the information used, must be considered when analyzing results.

One usual criticism to bibliometric studies is that they do not necessarily take into consideration the quality of research instead focusing in its impact. Taking quality in mind and relating specifically to our study, it can be argued that data could have been restricted to articles published in top rated journals. In our view, that would result in a sample too small to allow a comprehensive view of e-government research in the IA Community, in particular because, as it was demonstrated, e-government research is very heterogeneous in IA. Such a restriction would also aggravate the underrepresentation of documents written in languages other than English.

\section{Conclusions}

In this article we have presented and discussed the results of a bibliometric analysis on e-government research based on documents authored by researchers affiliated to IA countries. The conclusions that arise from the study are that: (i) e-government research in the IA Community is very heterogeneous; (ii) this heterogeneity can be explained by the maturity of public policies, namely those concerning the development of e-government and the promotion of research; (iii) despite this heterogeneity, there are relatively homogenous groups of countries, including expectant, emerging, evolving and leading countries; (iv) most publications (overall and by the most impacting authors) are made in technical sciences while having greater impact when published in social sciences; (v) contrary to what happens in the world, the production in IA is still growing; (vi) when compared to the world, there is a trend towards the research of citizenship related themes such as transparency and citizen's participation, including at the local government level and involving social media; (vii) this trend can be explained by the specific IA context concerning the social relevance of corruption and the quality of democracy; (viii) there are research subjects, such as e-services, 
service quality, security, privacy, and trust, that are underrepresented; and (ix) international cooperation with the leading countries in the Community proved to be extremely relevant for the development of the evolving countries.

Considering the results, there is the opportunity to further develop e-government research in the IA Community: the study universe is still likely to widen up as more countries reach more developed levels of e-government; the Community has distinctive features that make it interesting as an object of study; there are research themes that can be further explored; and there is the potential to attract more researchers to the e-government research effort. There is also the opportunity to further develop the cooperation within the IA Community and thus reinforce the development of e-government research: international cooperation between the most productive teams can be strengthened; cooperation between leading and evolving countries can continue to evolve; and cooperation can be extended to the emerging and the expectant countries. To seize these opportunities, public policies are crucial: countries have to continue to develop their national e-government programs and support their researchers and their internationalization efforts. But there is also space for multilateral initiatives, for example by the Organization of American States (OEA), in the scope of the EU cooperation with third countries, or at the IA level, through OEI.

This last possibility is probably the most promising. Indeed, the creation of an egovernment program at OEI would allow leveraging the existing cultural and political links to generate more and better research in e-government. Such a program could finance transnational research initiatives, international mobility, and specific conferences and workshops. Those would benefit both the most and least developed countries, allowing more authors, research institutions, and countries to reach higher levels of production and visibility and, simultaneously, potentiating the results of the already most active research teams. Considering that e-government development and research are associated, such a program could also combine a non-academic component and thus promote cooperation between researchers, practitioners and decision-makers at the IA level. This would promote mutual reinforcement between e-government research and e-government development at the IA level and in the IA Community.

But while such an initiative does not take place, individual researchers, research teams and institutions can continue to mobilize their efforts and use the available funds to 
strengthen IA cooperation. This study can contribute to the aforementioned purpose as a relevant source of information. Researchers interested in e-government can use it to identify foreign partners and benchmark their research, as research managers and research policy makers can use it as an input to research policy and internationalization.

The study also allows the conclusion that while global production of e-government research might already be losing momentum and if the IA Community can be seen as an example for other regions of the globe, there is still room for progress in developing countries. Thus, the decrease of e-government research as visible from international publication databases can be counteracted by fostering both e-government development and e-government research in those countries. To achieve this, special attention should be given to e-government specific challenges and constraints in developing countries and to understudied themes in those countries, namely by the international community and in cooperation with local researchers.

\section{References}

Alcaide-Muñoz, L., Rodríguez-Bolívar, M. P., Cobo, M. J., \& Herrera-Viedma, E. (2017). Analysing the scientific evolution of e-government using a science mapping approach. Government Information Quarterly, 34(3), 545-555. http://dx.doi.org/10.1016/j.giq.2017.05.002

Almeida, G. de O., Zouain, D. M., \& Mahecha, Y. L. R. (2014). The status of e-government research: a bibliometric study. Business and Management Review, 3(11), 7-22.

Aksnes, D. W. (2013). An overview of main bibliometric indicators: data sources, methods and applications. EuroCris membership meeting, University of Porto, 14-15 November. www.eurocris.up.pt/wp-content/uploads/2013/11/Porto_2013.pdf Accessed March 122016.

Archambault, E., Campbell, D., Gingras, Y., \& Larivière, V. (2009). Comparing bibliometric statistics obtained from the Web of Science and Scopus. Journal of the American Society for Information Science and Technology, 60(7), 1320-1326. http://dx.doi.org/10.1002/asi.21062 de Bellis, N. (2009). Bibliometrics and citation analysis: from the Science citation index to cybermetrics. Plymouth: Scarecrow Press. 
Braun, T., Glänzel, W., \& Schubert, A. (2006). A Hirsch-type index for journals.

Scientometrics, 69(1), 169-173. http://dx.doi.org/10.1007/s11192-006-0147-4

Canavero, F., Franceschini, F. Maisano, D., \& Mastrogiacomo, L. (2014). Impact of journals and academic reputations of authors: a structured bibliometric survey of the IEEE publication galaxy. IEEE Transactions on Professional Communication, 57(1), 17-40.

http://dx.doi.org/10.1109/TPC.2013.2255935

Cheng, S., \& Ding, L. (2012). A quantitative study on the research fronts of electronic government. In proceedings of the 2012 5th International Conference on Business Intelligence and Financial Engineering, BIFE 2012, 481-485.

http://dx.doi.org/10.1109/BIFE.2012.108

Ciocca, D. R., \& Delgado, G. (2017). The reality of scientific research in Latin America; an insider's perspective. Cell Stress and Chaperones, 22(6), 847-852.

http://dx.doi.org/10.1007/s12192-017-0815-8

Deb, G. K. (1999). Electronic governance: a vehicle for the new world order. Electronic Information \& Planning, 27(1), 29-33.

Dwivedi, Y. K. (2009). An analysis of e-Government research published in Transforming Government: People, Process and Policy (TGPPP). Transforming Government: People, Process and Policy, 3(1), 7-15. http://dx.doi.org/10.1108/17506160910940704

Dias, G. P. (2016). A decade of Portuguese research in e-government: Evolution, current standing, and ways forward. Electronic Government, 12(3), 201-222.

http://dx.doi.org/10.1504/EG.2016.078415

Erman, N., \& Todorovsky, L. (2010). Analyzing the structure of the EGOV conference community. In proceedings of the 9th IFIP WG 8.5 International Conference on Electronic Government, EGOV 2010, Lecture Notes in Computer Science, Vol. 6228, 73-84. http://dx.doi.org/10.1007/978-3-642-14799-9_7

Glänzel, W., Schubert, A., \& Czerwon, H. J. (1999). A bibliometric analysis of international scientific cooperation of the European Union (1985-1995). Scientometrics, 45(2), 185-202. http://dx.doi.org/10.1007/BF02458432 
Gobierno de El Salvador (2018). Gobierno presenta la estrategia de gobierno digital.

Gobierno de El Salvador, Secretaría Técnica y de Planificación.

http://www.secretariatecnica.gob.sv/gobierno-presenta-la-estrategia-de-gobierno-digital/ Accessed December 122018.

Gobierno de La República (2013). Estrategia Digital Nacional. Mexico City: Gobierno de La República. https://framework-

gb.cdn.gob.mx/data/institutos/edn/Estrategia_Digital_Nacional.pdf Accessed December 22 2018 .

Gobierno del Bicentenario (2018). Estrategia de Transformación Digital hacia la Costa Rica del Bicentenario 4.0. Gobierno del Bicentenario, Ministerio de Ciencia, Tecnología e Telecomunicaciones. https://micit.go.cr/transformaciondigitalcr/TransfDigitalCR.pdf Accessed December 312018.

Heeks, R., \& Bailur, S. (2007). Analyzing e-government research: perspectives, philosophies, theories, methods, and practice. Government Information Quarterly, 24(2), 243-265.

http://dx.doi.org/10.1016/j.giq.2006.06.005

Hirsch, J. E. (2007). Does the $h$ index have predictive power? In proceedings of the National Academy of Sciences of the United States of America, 104(49), 19193-19198.

http://dx.doi.org/10.1073/pnas.0707962104

Ismayilova, N. (2014). A bibliometric analysis of e-government research. In proceedings of the Elektron dövlat quruculuðu problemlari I Respublika elmi-praktiki konfransý, 93-95. http://ict.az/uploads/konfrans/GOOGLE_SCHOLAR_e-gov/28N.Ismayilova.pdf Accessed January 32018.

Jones, T., Huggett, S., \& Kamalski, J. (2011). Finding a way through the scientific literature: indexes and measures. World Neurosurgery, 76(1-2), 36-38.

http://dx.doi.org/10.1016/j.wneu.2011.01.015

Joseph, R. C. (2013). A structured analysis of e-government studies: trends and opportunities. Government Information Quarterly, 30(4), 435-440.

http://dx.doi.org/10.1016/j.giq.2013.05.006 
Milward, H. B., \& Snyder, L. O. (1996). Electronic government: Linking citizens to public organizations through technology. Journal of Public Administration Research and Theory, $6(2), 261-275$.

Ministério do Planejamento, Desenvolvimento e Gestão (2018). Estratégia de governança digital: Transformação digital - cidadania e governo. Brasilia: Ministério do Planejamento, Desenvolvimento e Gestão, Secretaria de Tecnologia da Informação e Comunicação. https://www.governodigital.gov.br/EGD/documentos/revisao-da-estrategia-de-governancadigital-2016-2019.pdf Accessed December 222018.

Nickson, A. (2011). Where is local government going in Latin America? A comparative perspective. Visby, Sweden: Swedish International Center for Local Democracy. https://www.icld.se/static/files/forskningspublikationer/icld-wp6-printerfriendly.pdf Accessed December 262018.

Organization of Ibero-American States for Education, Science and Culture (2018). http://www.oei.es/acercadelaoei.php Accessed 3 January 2018.

Pendlebury, D. A. (2009). The use and misuse of journal metrics and other citation indicators. Archivum Immunologiae et Therapiae Experimentalis, 57(1), 1-11.

http://dx.doi.org/10.1007/s00005-009-0008-y

Perritt, Jr., H. H. (1996). The information highway: on ramps, checkpoints, and tollbooths. Government Information Quarterly, 13(2), 143-158. http://dx.doi.org/10.1016/S0740$\underline{624 X(96) 90101-X}$

Presidencia del Consejo de Ministros (2018). Declaran de interés nacional el desarrollo del Gobierno Digital, la innovación y la economía digital con enfoque territorial, Decreto Supremo N 118-2018-PCM. El Peruano, 14740, 4-6.

https://busquedas.elperuano.pe/download/full/6sq011GgaU796zibdfRUzc Accessed December 312018.

Pritchard, A. (1969). Statistical bibliography or bibliometrics? Journal of Documentation, 25(4), 348-349.

Przeybilovicz, E., Coelho, T. R., \& Cunha, M. A. (2014). The Development of Studies on Electronic Government in Brazil: A bibliometric and sociometric study. In proceedings of the 
2014 International Conference on Information Resources Management (Conf-IRM 2014). http://aisel.aisnet.org/cgi/viewcontent.cgi?article=1025\&context=confirm2014 Accessed March 122016.

Relyea, H.C. (2002). E-gov: Introduction and overview. Government Information Quarterly, 19(1), 9-35. http://doi.org/10.1016/S0740-624X(01)00096-X

Rodríguez Bolívar, M. P., Alcaide Muñoz, L., \& López Hernández, A. M. (2016).

Scientometric study of the progress and development of e-government research during the period 2000-2012. Information Technology for Development, 22(1), 36-74.

http://dx.doi.org/10.1080/02681102.2014.927340

Rogers, E. M. (2003). Diffusion of Innovations, $5^{\text {th }}$ ed. New York: The Free Press.

Transparency International (2018). Corruption Perception Index 2017.

https://www.transparency.org/cpi Accessed December 262018.

United Nations (2016). UN e-government survey 2016.

https://publicadministration.un.org/egovkb/en-us/reports/un-e-government-survey-2016 Accessed July 312018.

World Bank (2018). World Bank Open Data, Science \& Technology.

https://data.worldbank.org/topic/science-and-technology Accessed July 312018. 
Table 1. Number of documents, number of citations, average number of citations per document, and $h$-index by IA country, between 2003 and 2017 .

\begin{tabular}{|c|c|c|c|c|}
\hline Country & Documents & Citations & $\begin{array}{l}\text { Average } \\
\text { citations }\end{array}$ & $h$-index \\
\hline Spain & 423 & 3317 & 7.84 & $\overline{31}$ \\
\hline Brazil & 275 & 1059 & 3.85 & 17 \\
\hline Portugal & 163 & 589 & 3.61 & 12 \\
\hline Mexico & 140 & 1312 & 9.37 & 18 \\
\hline Argentina & 45 & 147 & 3.27 & 5 \\
\hline Chile & 38 & 245 & 6.45 & 6 \\
\hline Ecuador & 37 & 25 & 0.68 & 4 \\
\hline Colombia & 32 & 32 & 1.00 & 2 \\
\hline Uruguay & 18 & 38 & 2.11 & 3 \\
\hline Costa Rica & 11 & 10 & 0.91 & 1 \\
\hline Peru & 11 & 2 & 0.18 & 2 \\
\hline Venezuela & 9 & 8 & 0.89 & 2 \\
\hline Puerto Rico & 5 & 19 & 3.80 & 3 \\
\hline Dominican Republic & 2 & 16 & 8.00 & 2 \\
\hline Bolivia & 2 & 0 & 0.00 & 0 \\
\hline El Salvador & 1 & 1 & 1.00 & 1 \\
\hline Honduras & 1 & 1 & 1.00 & 1 \\
\hline Paraguay & 1 & 0 & 0.00 & 0 \\
\hline
\end{tabular}


Table 2. Spearmen's correlations between the number of documents published and citations received and the UN e-Government Development Index (2016), The UN e-Participation Index (2016), the number of scientific and technical journal articles (2016), the Research and development expenditure in percentage of the GDP (average 2003-2017), and the number of researchers in R\&D per million people (average 2003-2017).

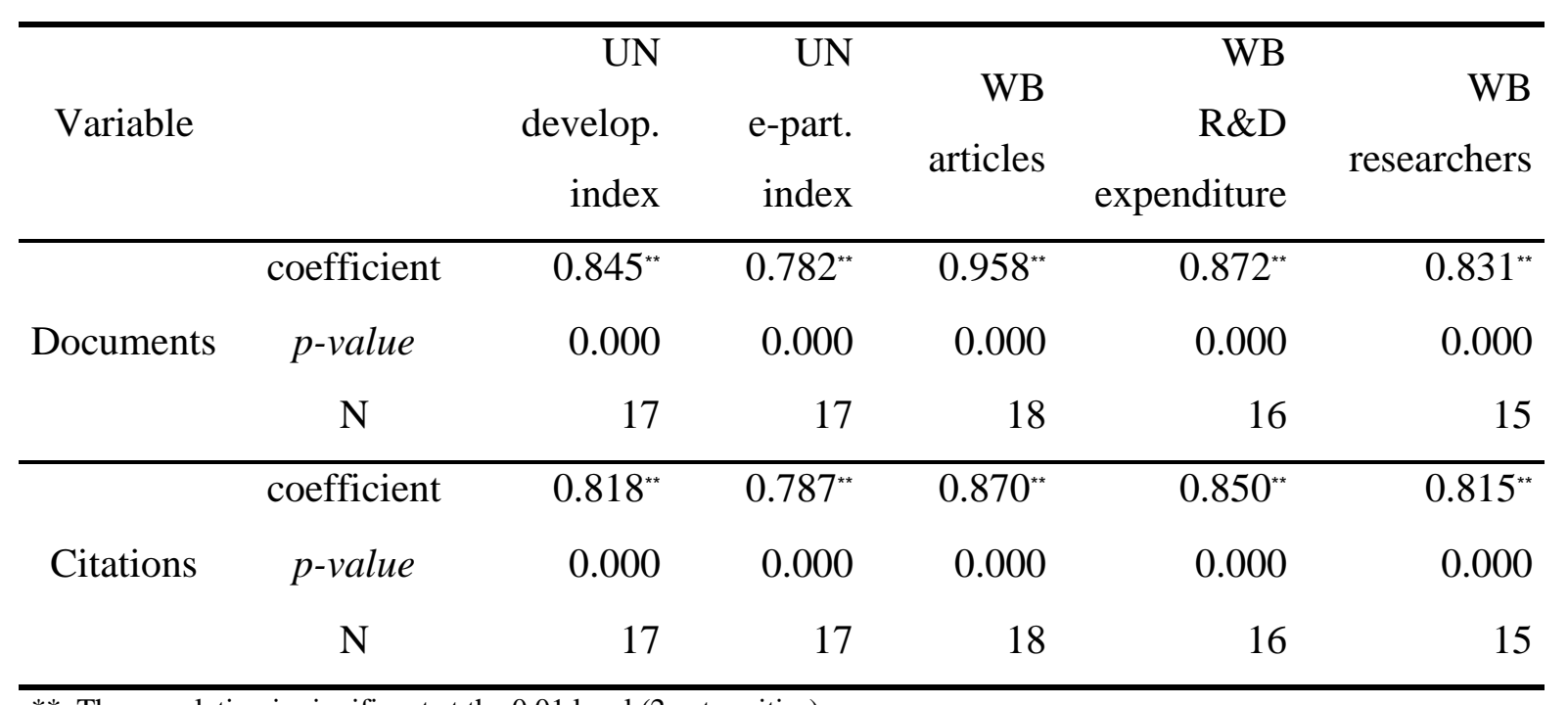


Table 3. Number of documents, percentage of documents, number of citations, percentage of citations, and average number of citations per document for derived non-overlapping subject areas.

\begin{tabular}{lrrrrr}
\hline Derived subject area & Documents & $\begin{array}{r}\text { Percentage of } \\
\text { documents }\end{array}$ & Citations & $\begin{array}{r}\text { Percentage of } \\
\text { citations }\end{array}$ & $\begin{array}{r}\text { Average } \\
\text { citations }\end{array}$ \\
\hline Computer Science & 589 & $52.2 \%$ & 1886 & $29.0 \%$ & 3.20 \\
Social Sciences & 261 & $23.1 \%$ & 3194 & $49.1 \%$ & 12.24 \\
Transversal to both areas & 168 & $14.9 \%$ & 1087 & $16.7 \%$ & 6.47 \\
None of the areas & 111 & $9.8 \%$ & 333 & $5.1 \%$ & 3.00 \\
\hline
\end{tabular}


Table 4. Percentage of documents worldwide and in the IA Community that address the main e-government research themes (absolute and percentage differences between those percentages are also represented).

\begin{tabular}{lrrrr}
\hline Research Theme & World & IA & $\begin{array}{r}\text { Absolut } \\
\text { difference }\end{array}$ & $\begin{array}{r}\text { Relative } \\
\text { difference }\end{array}$ \\
\hline e-participation & $11 \%$ & $18 \%$ & 7 p.p. & $65 \%$ \\
transparency and accountability & $21 \%$ & $33 \%$ & 12 p.p. & $57 \%$ \\
social media & $8 \%$ & $12 \%$ & 4 p.p. & $51 \%$ \\
interoperability and integration & $28 \%$ & $36 \%$ & 8 p.p. & $27 \%$ \\
usability and accessibility & $16 \%$ & $19 \%$ & 3 p.p. & $19 \%$ \\
local government & $36 \%$ & $41 \%$ & 5 p.p. & $13 \%$ \\
knowledge management & $15 \%$ & $16 \%$ & 2 p.p. & $11 \%$ \\
government agencies & $10 \%$ & $11 \%$ & 1 p.p. & $10 \%$ \\
architectures and technologies & $31 \%$ & $33 \%$ & 2 p.p. & $7 \%$ \\
e-government services & $44 \%$ & $39 \%$ & -5 p.p. & $-11 \%$ \\
digital divide & $12 \%$ & $10 \%$ & -2 p.p. & $-15 \%$ \\
adoption and acceptance & $33 \%$ & $27 \%$ & -5 p.p. & $-16 \%$ \\
decision support and decision making & $18 \%$ & $15 \%$ & -3 p.p. & $-18 \%$ \\
security, privacy and trust & $43 \%$ & $34 \%$ & -9 p.p. & $-21 \%$ \\
service quality & $11 \%$ & $9 \%$ & -3 p.p. & $-23 \%$ \\
\hline & & & & \\
\hline & & & &
\end{tabular}


Table 5. Country, number of documents, number of citations, average number of citations per article, $h$-index and percentage of documents published in derived non-overlapping subject categories for all the authors affiliated to institution in IA countries with eight or more documents in the database, between 2003 and 2017.

\begin{tabular}{|c|c|c|c|c|c|c|c|c|c|}
\hline Author & Country & Doc. & Cit. & Av. Cit. & $h$-ind. & $C S$ & $S S$ & Both & None \\
\hline Gil-Garcia, J.R. & USA & 68 & 1009 & 14.84 & 14 & $51 \%$ & $35 \%$ & $7 \%$ & $\overline{7 \%}$ \\
\hline Luna-Reyes, L.F. & Mexico & 45 & 526 & 11.69 & 11 & $44 \%$ & $31 \%$ & $16 \%$ & $9 \%$ \\
\hline Sandoval-Almazan, R. & Mexico & 32 & 305 & 9.53 & 6 & $63 \%$ & $19 \%$ & $19 \%$ & \\
\hline Bolívar, M.P.R. & Spain & 31 & 295 & 9.52 & 9 & $6 \%$ & $61 \%$ & $23 \%$ & $10 \%$ \\
\hline Sabucedo, L.Á. & Spain & 25 & 67 & 2.68 & 5 & $72 \%$ & & $20 \%$ & $8 \%$ \\
\hline Rifon, L.A. & Spain & 23 & 60 & 2.61 & 5 & $74 \%$ & & $17 \%$ & $9 \%$ \\
\hline Dias, G.P. & Portugal & 22 & 145 & 6.59 & 7 & $77 \%$ & & $18 \%$ & $5 \%$ \\
\hline Muñoz, L.A. & Spain & 20 & 48 & 2.40 & 4 & $10 \%$ & $50 \%$ & $25 \%$ & $15 \%$ \\
\hline Joia, L.A. & Brazil & 19 & 101 & 5.32 & 5 & $26 \%$ & $42 \%$ & $32 \%$ & \\
\hline Estevez, E. & Argentina & 15 & 65 & 4.33 & 5 & $87 \%$ & & $7 \%$ & $7 \%$ \\
\hline Luna, D.E. & Mexico & 15 & 33 & 2.20 & 3 & $80 \%$ & & $13 \%$ & $7 \%$ \\
\hline López Hernández, A.M. & Spain & 14 & 88 & 6.77 & 6 & & $71 \%$ & $14 \%$ & $14 \%$ \\
\hline Puron-Cid, G. & Mexico & 13 & 28 & 2.15 & 2 & $54 \%$ & $38 \%$ & & $8 \%$ \\
\hline Rocha, Á. & Portugal & 12 & 93 & 7.75 & 6 & $58 \%$ & $17 \%$ & $17 \%$ & $8 \%$ \\
\hline Sá, F. & Portugal & 12 & 93 & 7.75 & 6 & $58 \%$ & $17 \%$ & $17 \%$ & $8 \%$ \\
\hline Misuraca, G. & Spain & 12 & 78 & 6.50 & 5 & $33 \%$ & $42 \%$ & $17 \%$ & $8 \%$ \\
\hline Criado, J.I & Spain & 11 & 167 & 13.92 & 6 & $18 \%$ & $64 \%$ & $18 \%$ & \\
\hline Picazo-Vela, S. & Mexico & 11 & 158 & 14.36 & 5 & $55 \%$ & $18 \%$ & $18 \%$ & $9 \%$ \\
\hline Janowski, T. & Poland & 11 & 106 & 9.64 & 5 & $73 \%$ & $9 \%$ & $9 \%$ & $9 \%$ \\
\hline Maciel, C. & Brazil & 11 & 95 & 8.64 & 4 & $82 \%$ & & $18 \%$ & \\
\hline Reinherd, N. & Brazil & 11 & 18 & 1.64 & 3 & $55 \%$ & & $45 \%$ & \\
\hline Pardo, T.A. & USA & 10 & 102 & 10.20 & 5 & $70 \%$ & $10 \%$ & $10 \%$ & $10 \%$ \\
\hline Matheus, R. & Netherl. & 10 & 36 & 3.60 & 4 & $100 \%$ & & & \\
\hline Torres, L. & Spain & 9 & 755 & 83.89 & 6 & $33 \%$ & $44 \%$ & $22 \%$ & \\
\hline
\end{tabular}




\begin{tabular}{|c|c|c|c|c|c|c|c|}
\hline Ribeiro, M.M. & Brazil & 9 & 35 & 3.89 & 4 & $100 \%$ & \\
\hline Royo, S. & Spain & 8 & 657 & 82.13 & 6 & $25 \%$ & $50 \% \quad 25 \%$ \\
\hline Pina, V. & Spain & 8 & 468 & 58.50 & 5 & $38 \%$ & $38 \% \quad 25 \%$ \\
\hline
\end{tabular}


Table 6. Country, number of documents, number of citations, average number of citations per article and $h$-index for all the affiliation institution with 13 or more documents in the database, between 2003 and 2017.

\begin{tabular}{|c|c|c|c|c|c|}
\hline Research institution & Country & Doc. & Cit. & Av. cit. & $h$-index \\
\hline $\begin{array}{l}\text { Centro de Investigacioin y Docencia } \\
\text { Economicas A.C. }\end{array}$ & Mexico & 57 & 675 & 11.84 & 13 \\
\hline Universidad de las Americas Puebla & Mexico & 48 & 530 & 11.04 & 11 \\
\hline Universidad de Vigo & Spain & 47 & 175 & 3.72 & 8 \\
\hline Universidad de Granada & Spain & 46 & 356 & 7.74 & 10 \\
\hline Universidade de São Paulo & Brazil & 46 & 183 & 3.98 & 8 \\
\hline $\begin{array}{l}\text { University at Albany State University of } \\
\text { New York }\end{array}$ & EUA & 44 & 456 & 10.36 & 9 \\
\hline Universidade do Minho & Portugal & 38 & 98 & 2.58 & 5 \\
\hline Fundacao Getulio Vargas & Brazil & 36 & 182 & 5.06 & 7 \\
\hline Universidade Estadual de Campinas & Brazil & 34 & 287 & 8.44 & 7 \\
\hline Universidad de Zaragoza & Spain & 31 & 976 & 31.48 & 12 \\
\hline Universidade de Aveiro & Portugal & 26 & 157 & 6.04 & 7 \\
\hline Universidade Federal do Rio de Janeiro & Brazil & 25 & 129 & 5.16 & 5 \\
\hline Universidad Politècnica de València & Spain & 22 & 288 & 13.09 & 6 \\
\hline $\begin{array}{l}\text { Universidad Autonoma del Estado de } \\
\text { Mexico }\end{array}$ & Mexico & 20 & 58 & 2.90 & 5 \\
\hline Universidad de Oviedo & Spain & 20 & 57 & 2.85 & 3 \\
\hline Universidad Autonoma de Madrid & Spain & 19 & 159 & 8.37 & 5 \\
\hline Universidat d'Alacant & Spain & 19 & 83 & 4.37 & 5 \\
\hline Universidade de Coimbra & Portugal & 18 & 83 & 4.61 & 6 \\
\hline Universidad Politecnica de Madrid & Spain & 18 & 61 & 3.39 & 4 \\
\hline Universidade de Sevilla & Spain & 16 & 35 & 2.19 & 4 \\
\hline Universidade de Brasilia & Brazil & 16 & 13 & 0.81 & 2 \\
\hline $\begin{array}{l}\text { EC Joint Research Center Institute for } \\
\text { Prospective Technological Studies }\end{array}$ & Spain & 15 & 64 & 4.27 & 5 \\
\hline
\end{tabular}




\begin{tabular}{llllll} 
Universidade do Estado do Rio de Janeiro & Brazil & 14 & 39 & 2.79 & 3 \\
Universidad Nacional del Sur & Argentina & 14 & 19 & 1.36 & 4 \\
Universidade Federal Fluminense & Brazil & 13 & 89 & 6.85 & 4 \\
Universidad Complutense de Madrid & Spain & 13 & 61 & 4.69 & 5 \\
\hline
\end{tabular}

Table 7. Number of articles co-authored with authors affiliated to institutions in any foreign country (international documents), number of documents co-authored with authors affiliated to institutions in any other IA country, relative weight of international documents in the total number of documents published, and relative weight of IA international documents in the total number of documents published, per IA country.

\begin{tabular}{lrrrr}
\hline Country & $\begin{array}{r}\text { International } \\
\text { documents }\end{array}$ & $\begin{array}{r}\text { International } \\
\text { IA documents }\end{array}$ & $\begin{array}{r}\text { International } \\
\text { weight }\end{array}$ & IA weigh \\
\hline Argentina & 22 & 10 & $49 \%$ & $22 \%$ \\
Brazil & 51 & 13 & $19 \%$ & $5 \%$ \\
Chile & 21 & 9 & $55 \%$ & $24 \%$ \\
Colombia & 12 & 9 & $38 \%$ & $28 \%$ \\
Dominican Republic & 1 & 1 & $50 \%$ & $50 \%$ \\
Ecuador & 28 & 23 & $76 \%$ & $62 \%$ \\
Mexico & 59 & 7 & $42 \%$ & $5 \%$ \\
Peru & 7 & 6 & $64 \%$ & $55 \%$ \\
Portugal & 48 & 25 & $29 \%$ & $15 \%$ \\
Spain & 130 & 57 & $31 \%$ & $13 \%$ \\
Uruguay & 4 & 4 & $22 \%$ & $22 \%$ \\
Venezuela & 3 & 1 & $33 \%$ & $11 \%$ \\
\hline
\end{tabular}


Table 8. Detail of the number of articles affiliated jointly by each pair of IA countries, between 2003 and 2017.

\begin{tabular}{|c|c|c|c|c|c|c|c|c|c|c|c|c|}
\hline Country & 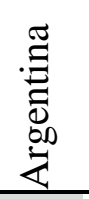 & $\begin{array}{l}\overline{\mathbb{N}} \\
\stackrel{\widetilde{n}}{n} \\
\end{array}$ & $\stackrel{\frac{e}{\exists}}{\vec{U}}$ & $\begin{array}{l}\frac{\pi}{0} \\
\frac{0}{0} \\
0 \\
0 \\
0\end{array}$ & $\begin{array}{l}\dot{\otimes} \\
\stackrel{2}{1} \\
\dot{0} \\
\dot{0}\end{array}$ & 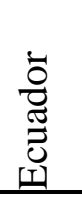 & $\begin{array}{l}\stackrel{0}{0} \\
\sum_{z}^{0} \\
\end{array}$ & ᄅ্ত & 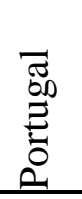 & $\begin{array}{l}: \Xi \\
\tilde{\Xi} \\
\text { ڤ }\end{array}$ & 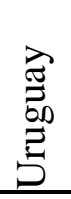 & $\begin{array}{l}\frac{\pi}{0} \\
\stackrel{0}{N} \\
\stackrel{0}{0} \\
>\end{array}$ \\
\hline Argentina & & 1 & 1 & 1 & & & & & 2 & 6 & & 1 \\
\hline Brazil & 1 & & 3 & 2 & 1 & & & 1 & 7 & 2 & & \\
\hline Chile & 1 & 3 & & 4 & & & & & & 4 & & \\
\hline Colombia & 1 & 2 & 4 & & & & 2 & & & 3 & 1 & \\
\hline Dom. Republic & & 1 & & & & & & & & & & \\
\hline Ecuador & & & & & & & & 5 & & 18 & & \\
\hline Mexico & & & & 2 & & & & & & 6 & & \\
\hline Peru & & 1 & & & & 5 & & & & & & \\
\hline Portugal & 2 & 7 & & & & & & & & 16 & & \\
\hline Spain & 6 & 2 & 4 & 3 & & 18 & 6 & & 16 & & 3 & \\
\hline Uruguay & & & & 1 & & & & & & 3 & & \\
\hline Venezuela & 1 & & & & & & & & & & & \\
\hline
\end{tabular}




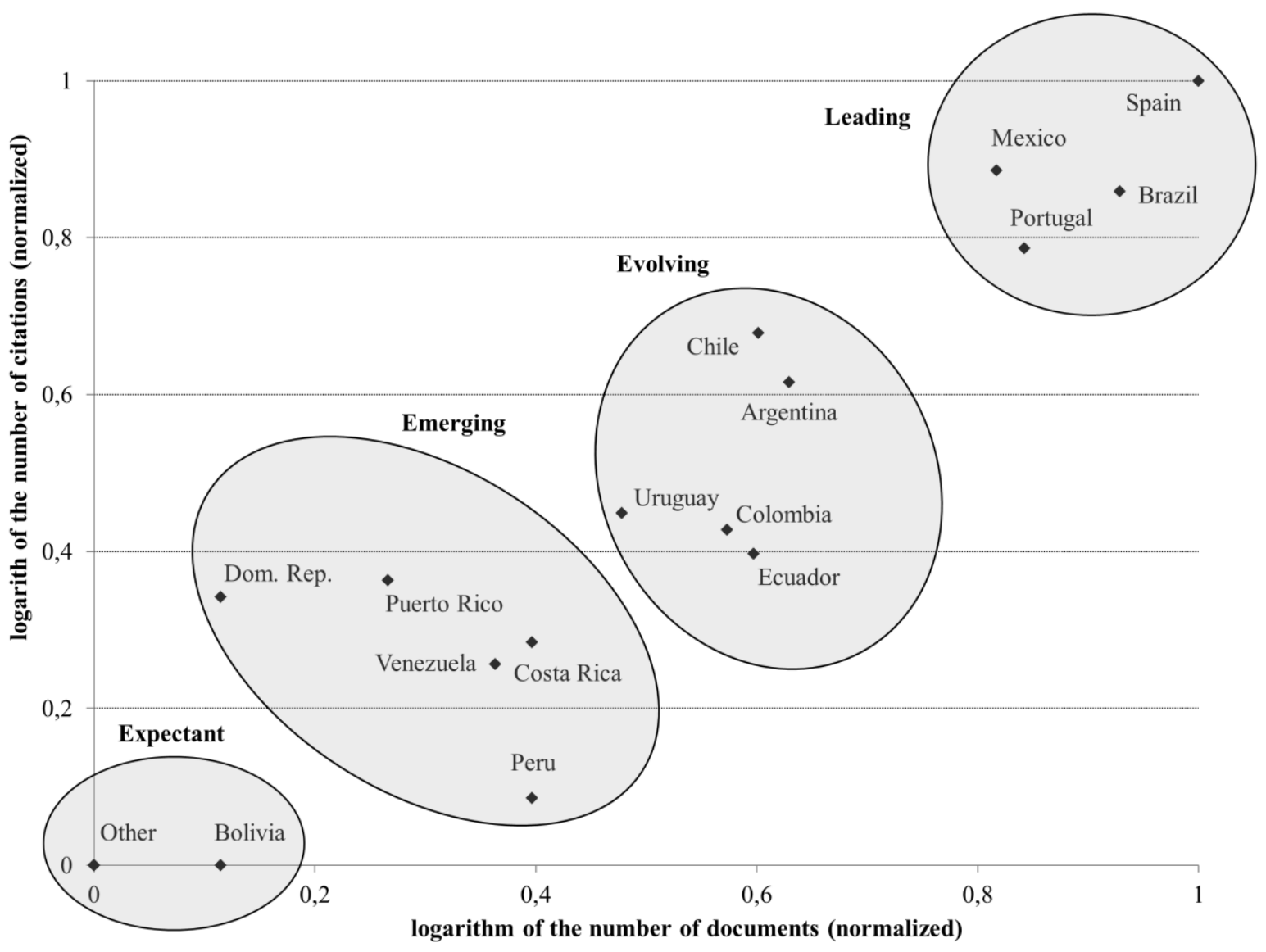

Figure 1. Country clustering based on the number of documents published and citations received (K-Means, 4 clusters). 


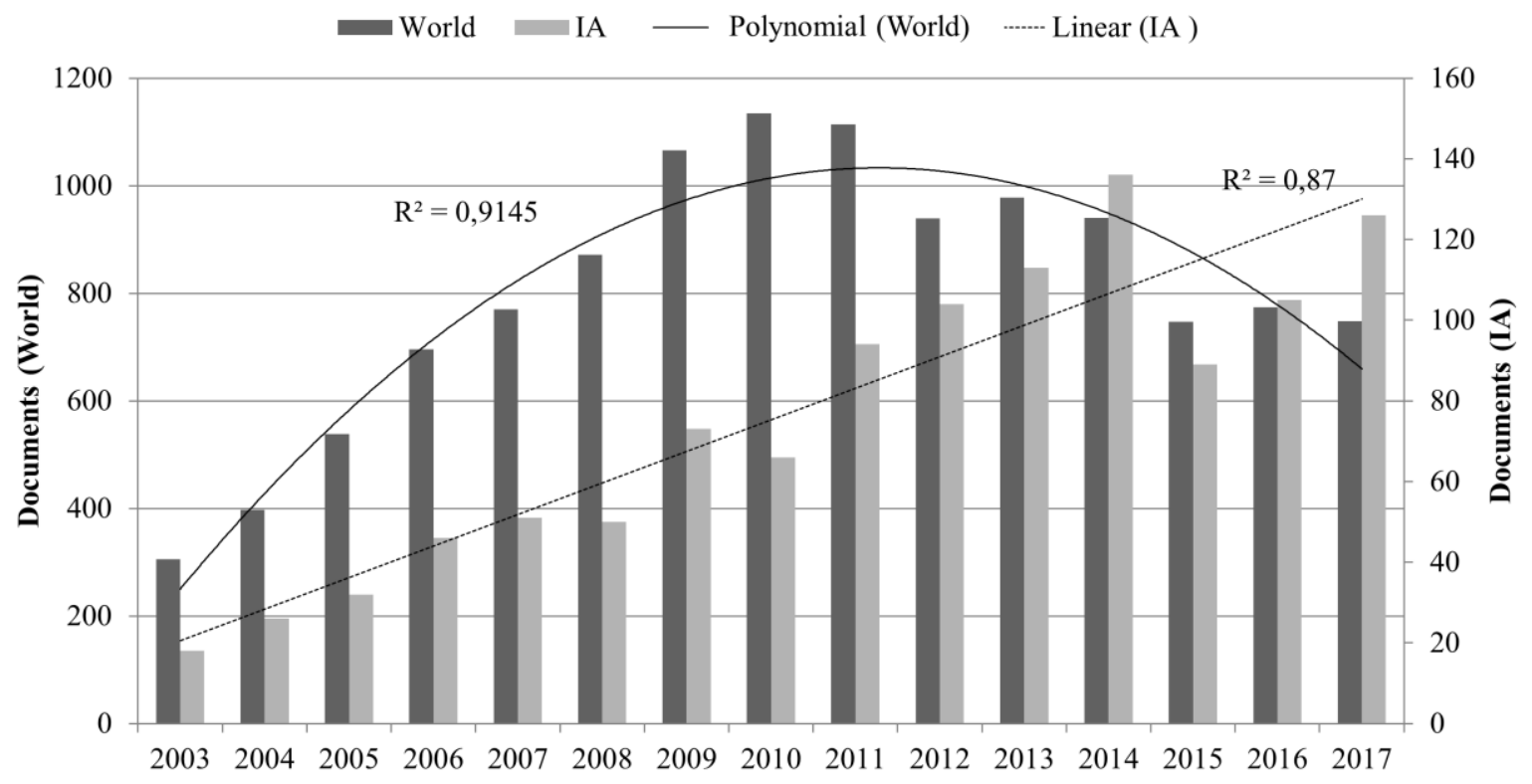

Figure 2. Evolution of the number of documents published worldwide and by authors affiliated to IA institutions, from 2003 to 2017, with trend lines. 


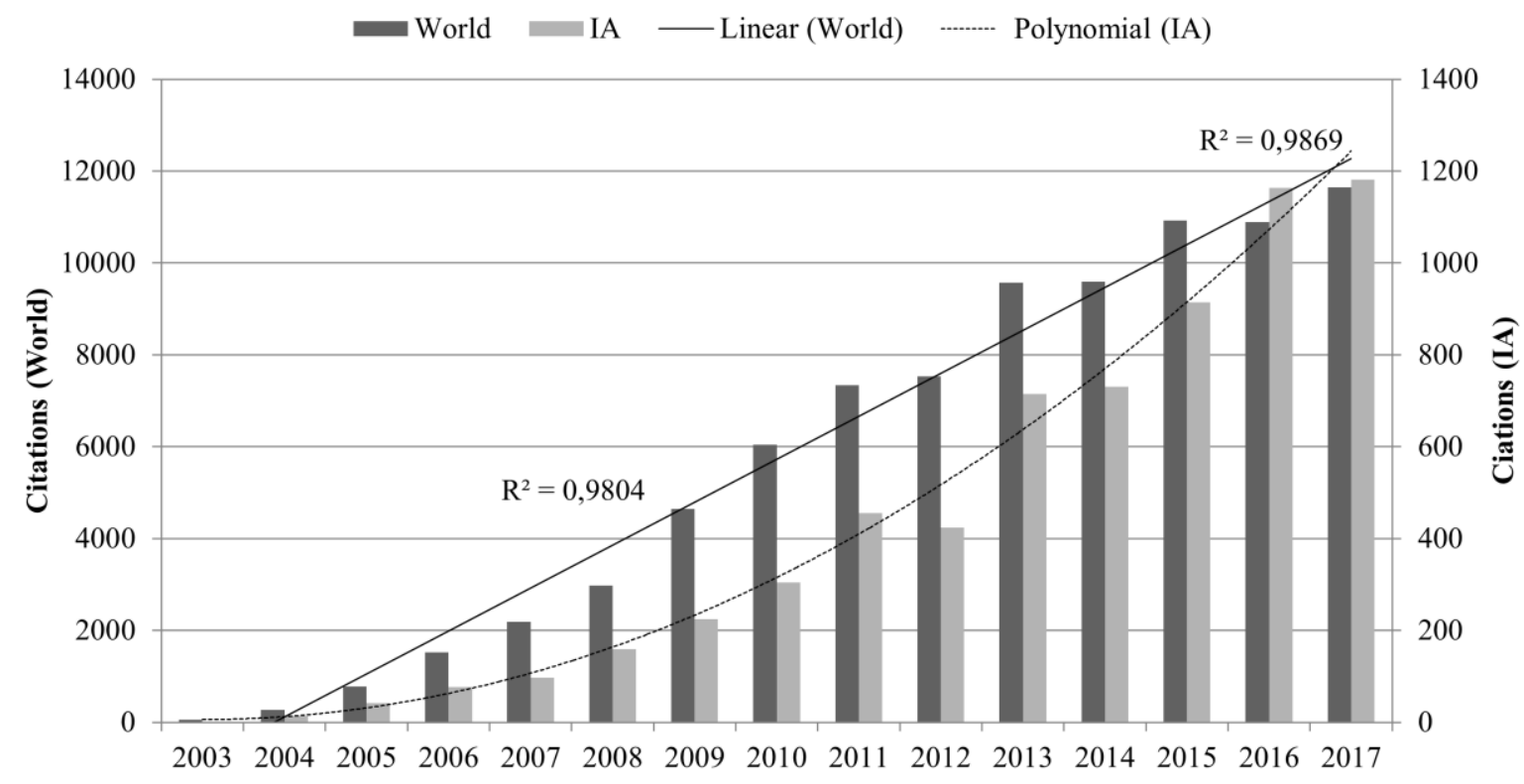

Figure 3. Evolution of the number of citations received worldwide and by authors affiliated to IA institutions, up to the end of 2017 , with trend lines. 


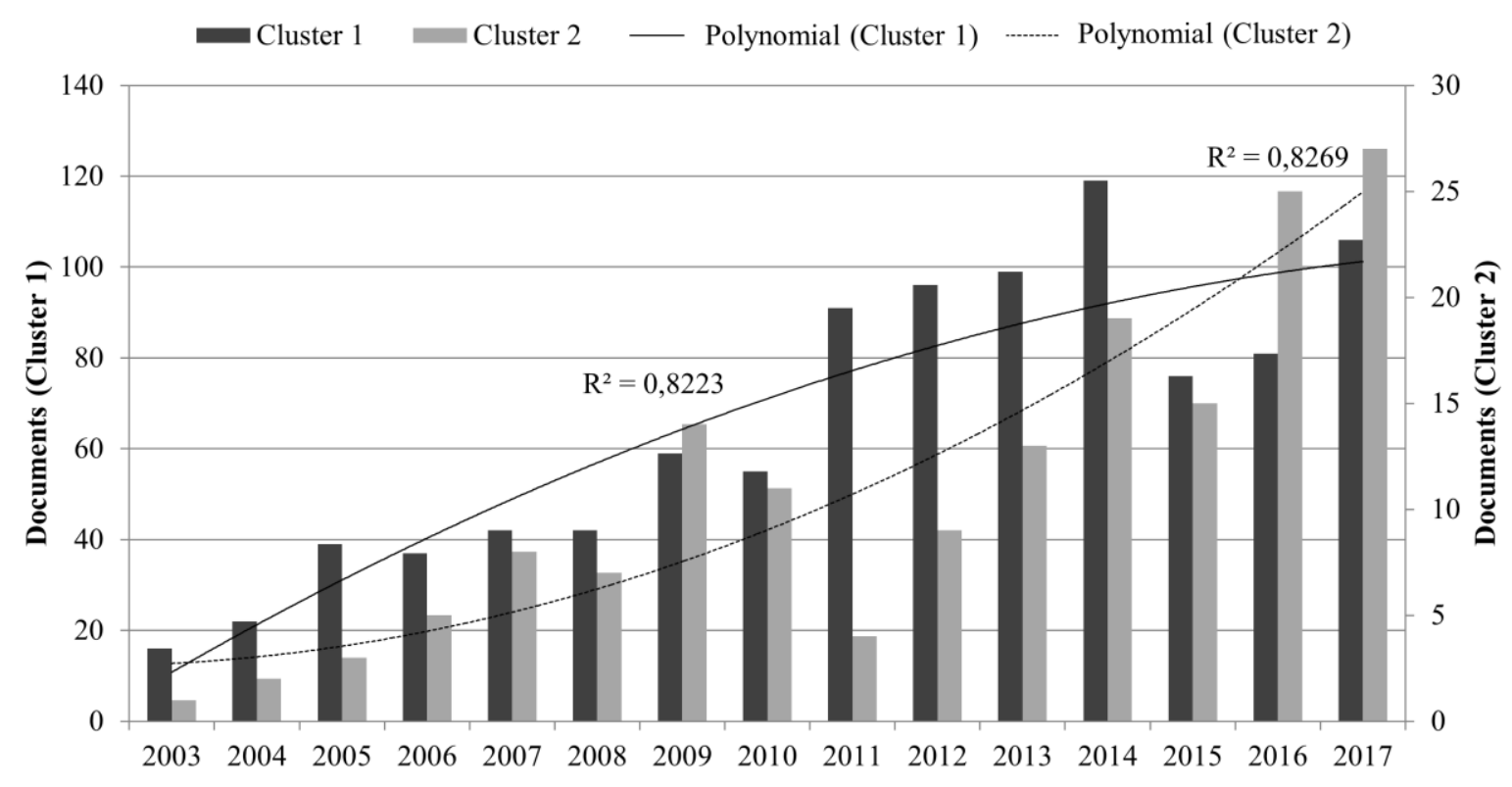

Figure 4. Evolution of the number of documents published by authors affiliated to countries in Cluster 1 and in Cluster 2, from 2003 to 2017, with trend lines. 


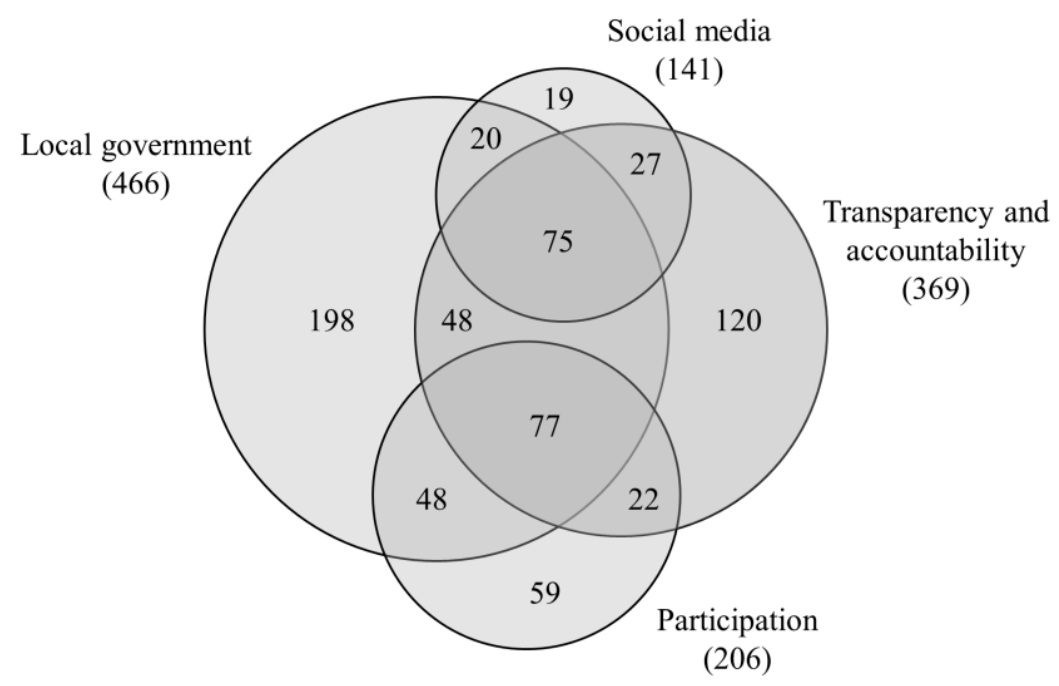

Figure 5. Venn diagram representing the most significant intersections between the identified themes (figures refer to the total number of documents in each subset, intersection between 'social media' and 'participation' is not represented). 